\title{
Towards a strong virtue ethics for nursing practice
}

\author{
Alan E. Armstrong $\mathrm{RN}(\mathrm{G}) \mathrm{BA}($ Hons) $\mathrm{MA} \mathrm{PhD}$ \\ Department of Nursing, University of Central Lancashire, Preston, Lancashire, UK
}

Abstract

Illness creates a range of negative emotions in patients including anxiety, fear, powerlessness, and vulnerability. There is much debate on the 'therapeutic' or 'helping' nurse-patient relationship. However, despite the current agenda regarding patient-centred care, the literature concerning the development of good interpersonal responses and the view that a satisfactory nursing ethics should focus on persons and character traits rather than actions, nursing ethics is dominated by the traditional obligation, act-centred theories such as consequentialism and deontology. I critically examine these theories and the role of duty-based notions in both general ethics and nursing practice. Because of wellestablished flaws, I conclude that obligation-based moral theories are incomplete and inadequate for nursing practice. I examine the work of Hursthouse on virtue ethics' action guidance and the v-rules. I argue that the moral virtues and a strong (action-guiding) version of virtue ethics provide a plausible and viable alternative for nursing practice. I develop an account of a virtue-based helping relationship and a virtuebased approach to nursing. The latter is characterized by three features: (1) exercising the moral virtues such as compassion; (2) using judgement; and (3) using moral wisdom, understood to include at least moral perception, moral sensitivity, and moral imagination. Merits and problems of the virtue-based approach are examined. I relate the work of MacIntyre to nursing and I conceive nursing as a practice: nurses who exercise the virtues and seek the internal goods help to sustain the practice of nursing and thus prevent the marginalization of the virtues. The strong practice-based version of virtue ethics proposed is contextdependent, particularist, and relational. Several areas for future philosophical inquiry and empirical nursing research are suggested to develop this account yet further.

Correspondence: Alan E. Armstrong, Senior Lecturer in Nursing, Department of Nursing, Greenbank Building, Room 310, University of Central Lancashire, Preston, Lancashire PR1 2HE, UK. Tel.: +4401772 893723; fax: +44 01772 892998; e-mail: aearmstrong@uclan.ac.uk and aearmstrong@btinternet.com 
Keywords: moral virtues, virtue ethics, obligation-based moral theories, Hursthouse, MacIntyre, moral wisdom.

\section{Introduction}

In this paper, I argue for a strong - action-guiding version of virtue ethics for contemporary nursing practice. In Illness, emotions, and the nurse-patient relationship section, I examine some typical emotional responses to illness, discuss several aspects of the therapeutic nurse-patient relationship, and acknowledge the importance of qualities such as kindness and honesty in such a relationship. In The virtues section, I turn to moral philosophy and examine the moral virtues including some merits and problems. Next in Obligation-based moral theories in general and nursing ethics section, I critique obligation-based moral theories in both general and nursing ethics. I reject these moral theories because of their incompleteness and inadequacy. In Virtue ethics: tenets, types, merits, and problems section, I provide an overview of virtue ethics and acknowledge the plausibility of a strong version of virtue ethics. In The virtue-based approach to moral decision making in nursing practice section, I provide a tentative account of a virtue-based approach to moral decision making in nursing practice. In the final section, MacIntyre's account of the virtues and the virtue-based approach in nursing practice, I relate the work of MacIntyre (1985) to my conception of the virtue-based approach.

\section{Illness, emotions, and the nurse-patient relationship}

\section{IIIness and emotions}

Illness can affect one at any point in the lifespan. Illness becomes part of the person's life. It can interfere with and cause problems in one's daily living. One's experience of illness is a personal phenomenon; illness affects people in markedly different ways.

During infancy and childhood, children are dependent on others - usually parents and guardians - to take care of them and help them to fare well in life.
Later, in old age, the reverse might occur: children may be involved in helping and caring for their parents. During one's life, help and support is sometimes required from other people including one's spouse, friends, and family members. The need for help is intensified during periods of both physical and mental illness; during such illness, humans need other humans to help them survive, recover, and fare well.

Illness is one of the features that can characterize one's life; this is especially true if one suffers from prolonged and chronic illness, either physical or mental. The extent to which illness becomes part of, or takes over, one's life depends on several factors including the causation, symptamatology, and prognosis of the illness and individual personality traits and coping mechanisms (e.g. Crowley et al., 2003; Narayanasamy, 2004). Irrespective of these factors, illness becomes part of one's life story. Illness helps to define one's life and the sorts of lives people can live. An important point about illness is that it is a feature of human life that can be shared with others, through, for example, conversation. By sharing these experiences, people can construct a narrative account of their illness (e.g. Bulow, 2003; Clouston, 2003; Zakrzewski \& Hector, 2004).

Illness, whether it is life-threatening or not, causes a range of emotional responses in the person including feelings of anxiety, fear, powerlessness, and vulnerability. Feeling anxious and worried is natural during illness. The fear of physical symptoms such as pain and the fear of dying are also natural responses to illness. Feelings created by illness and the features imposed upon one by the dehumanizing process of hospitalization (e.g. Norman, 1980; Miller, 1985; Hirschfeld, 2003) promote feelings of powerlessness. If patients cannot exert any control over their illness, environment, and care or if this is possible but only to a minimal extent, then feelings of powerlessness might naturally develop. Feelings of powerlessness and loss of control can be a particular feature of chronic Illness, including 
chronic mental illness. In the words of Pellegrino \& Thomasma (1993, p. 42),

sick persons must bare their weaknesses, compromise their dignity, and reveal intimacies of body and mind.

Patients might feel vulnerable because they are aware that there is potential to be hurt both physically and emotionally. Feelings of fear and powerlessness will perhaps contribute to a general sense of feeling vulnerable: being wide open to harm. These feelings can be intensified when the ill person requires help from nurses either at home or in hospital. Patients are reliant on nurses to relieve distressing symptoms, promote independence, and enable recovery. Ultimately, when one is hospitalized, one is dependent upon help from others, including nurses, to survive, recover, and fare well during and beyond illness.

\section{The nurse-patient relationship}

Since the middle part of the 20th century, the nursepatient relationship - seen in terms of human interactions, excellent communication skills, and mutual cooperation - has emerged as a central concept in nursing theory and practice. Literature (e.g. Skidmore, 1992; Wright, 1993; Monaghan, 1995; Speedy, 1999) identifies certain characteristics of a therapeutic nurse-patient relationship including the idea that this relationship should be patient-centred and collaborative. The development and sustenance of a therapeutic nurse-patent relationship is a core role of the nurse (e.g. Skidmore, 1992; Wright, 1993; Monaghan, 1995; Speedy, 1999). While this is a complex topic, it is possible to identify areas of convergence (e.g. Armstrong et al., 1999; Walker et al., 2000). These areas include the idea that nurses should (1) help the patient to survive and recover from illness; (2) promote the patient's independence; and (3) in terminal illness, alleviate physical symptoms such as pain and promote dignity.

At least, some patients believe that being a 'good' nurse and providing 'high'-quality care centres on nurses possessing and demonstrating several personal attributes, qualities or skills. Traits such as kindness, patience, and tolerance contribute to nurses delivering high-quality care (e.g. Beech \& Norman, 1995), while compassion is recognized as a crucial trait required by nurses to deliver morally good care (e.g. Armstrong et al., 2000).

The above conception of the nurse-patient relationship is held by patients to be extremely valuable, as valuable, if not more valuable, than other clinical interventions (Walker et al., 2000). Of course, this kind of helping relationship is only achievable if nurses make themselves available to patients, spend sufficient time with patients, and listen attentively to what patients have to say. Unfortunately, literature suggests that nurses are spending most of their time on administrative tasks and only a small proportion of their time is spent in direct contact with patients (e.g. Altschul, 1972; Sanson-Fisher et al., 1979; Hurst \& Howard, 1988; Martin, 1992; Whittington \& McLaughlin, 2000).

It seems sensible then to suggest that if 'high'-quality nursing care is to be delivered, critical reflection is required on several topics including (1) the role of a nurse; (2) the kind of interpersonal responses that nurses ought to demonstrate; and (3) the character traits that nurses ought to demonstrate in the delivery of nursing care.

Kindness and honesty are important for the development of a therapeutic nurse-patient relationship (e.g. Beech \& Norman, 1995; Armstrong et al., 2000). These qualities are character traits; more accurately, these qualities are examples of moral virtues. It is therefore prudent to turn to moral philosophy and examine the nature of the virtues.

\section{The virtues}

\section{Aristotle on virtue}

Ancient Greek philosophy (e.g. Irwin, 1999) provides an early account of the role of the virtues in human lives, understood in terms of human nature, the good life for humans and the notion of human flourishing. The central question posed by Aristotle (1980) in The Nicomachean Ethics is 'what is the good life for man?'. Crudely, his response was living the life of virtue according to reason and desires.

In Book Two of The Nicomachean Ethics, Aristotle states that the soul consists of three kinds of things: passions, faculties, and states of character. 
Aristotle believed virtue is neither passions nor faculties; 'all that remains is that they [the virtues] should be states of character' (Aristotle, 1980, p. 28). $\mathrm{He}$ distinguished between moral and intellectual virtue. The latter was taught through instruction and was split into scientific knowledge (episteme), intelligence (nous), technical skill (techne), wisdom (sophia), and practical wisdom (phronesis). Conversely, moral virtue was acquired through exercising the virtue, 'moral virtue comes about as a result of habit' (Aristotle, 1980, p. 28). The emphasis is on the word 'habitual'. Taking honesty as an example, someone who is honest on certain occasions - perhaps when it is convenient to be so - does not posses the virtue of honesty. On the Aristotelian view, the honest person is always honest. For Aristotle, the actions of a virtuous person spring from a steady unchangeable character.

\section{Assumptions about the meaning and use of 'virtue'}

One of the common criticisms of virtue ethics is that it is circular in character: that by being virtuous exercising virtues such as honesty - one is a morally good person but, to be morally 'good', one needs to be virtuous. While this is one of the traditional criticisms of virtue ethics, it does not fatally undermine the coherence of virtue ethics. The term 'virtue' derives from the ancient Greek word 'arête' and means 'an excellence of character' (Aristotle, 1980). I shall not here defend the coherence of virtue ethics further. However, with a fair degree of intellectual authority, several contemporary virtue ethicists counter the circular argument criticism (e.g. Slote, 1992, 2001; Hursthouse, 1999; Oakley \& Cocking, 2001).

\section{Virtues or vices?}

Aristotle's conception of a virtue fails to distinguish virtues from vices because the latter are also character traits manifested in habitual action. Pincoffs (1986) provides one account of how to resolve this problem. He claims that the virtues and vices should be thought of as qualities that persons think about in deciding whether someone should be avoided or sought. He writes

Some sorts of person we prefer; others we avoid.... The properties on our list can serve as reasons for preference or avoidance (Pincoffs, 1986, p. 78).

Regarding the vices, most people would probably wish to avoid meeting other people who are, for instance, cruel, callous, mean or dishonest. These kinds of character traits are not admirable either in us or in others.

\section{Virtues and roles}

Rachels (1999) provides a list of common virtues. Examples include so-called other-regarding virtues such as compassion, honesty, and patience. Social virtues include justice and examples of other virtues are assertiveness, temperance, and tolerance. The inculcation of the virtues depends upon one's roles. People's lives consist of many diverse roles and ends. Rachels's (1999) examples are an auto mechanic and a teacher. He believes that an auto mechanic should be honest, conscientious, and skilful, while a teacher should be articulate, patient, and knowledgeable. Imagine a lawyer whom I wish to act on my behalf. I would like her to be intelligent, articulate, and courageous. By exercising these traits, she will act well as my legal advocate.

\section{Virtues, character, and faring well}

According to contemporary moral philosophers (e.g. Hursthouse, 1999), moral virtues are character traits that dispose one, their possessor, to habitually act, think, and feel in certain ways.Rachels (1999, p. 178) believes that a virtue is 'a trait of character, manifested in habitual action that it is good for a person to have'. The moral virtues are those that it is good for everyone to have.

The virtues form part of one's character; they are an internal part of one's identity. Moral obligations and principles are external to the person; these social constructs are imposed upon people from the outside world e.g. professional obligations from the Nursing and Midwifery Council (NMC, 2004). Such obligations need to be understood, interpreted, and applied 
by people; hence, they are not necessarily compatible with the kind of person one is. The moral virtues are morally excellent character traits. Cultivating and exercising the moral virtues is instrumental to leading morally good lives. Exercising the moral virtues tends to help people to fare well in life and helps others fare well too. However, I stress that I am talking about faring well in moral terms. Being dishonest and cheating people might help one to become financially wealthy, but this is not living a morally good life. Cultivating the moral virtues will help one to act, think, and feel in morally excellent ways. I would add that the virtues should be regarded as morally admirable traits of character (Slote, 1992). People who exercise moral virtues deserve to be praised and admired because of the moral excellence of their deeds, thoughts, and feelings, and because it can be extremely difficult to cultivate the virtues.

\section{Why should the virtues be valued? The example of kindness}

The virtues are morally excellent character traits, which help people to lead morally good lives and deserve praise and admiration from others. A reasonable question is "what reasons are there for not valuing the virtues?' As noted earlier, the virtues might not be valued because it is not easy to be habitually virtuous; one only needs to think about an otherregarding virtue such as generosity to appreciate this point. If one does not wish to lead a life of altruism, then it is clear that one might not immediately understand the value of other-regarding virtues; furthermore, it is clear that valuing the virtues will also depend upon the particular virtue in question.

In an effort to demonstrate the value of the virtues, I will look at the example of kindness. Robert is a charity worker in Africa, helping to care for people who are sick and dying. He is kind towards others. $\mathrm{He}$ believes that being kind is crucial to his role because he can see that those whom he cares about are helped through his acts and feelings of kindness. Robert works consistently hard to be kind towards others. By acting, thinking, and feeling kindly, Robert carries out his role well and others are helped through his kindness. This example is limited to one other-regarding virtue, namely, kindness, and it could be accused of oversimplifying the truth. However, it serves to show how the virtues are important in human lives; how, in this scenario, Robert's kindness helped others to fare better in life and how it helped him to do well too. Exercising the moral virtues, especially otherregarding virtues such as kindness, is particularly important when working with people who are helpless and vulnerable.

\section{Advantages of the virtues: rich action guidance and the ' $v$-rules'}

Obligation-based ethicists argue that the virtuous person will have no idea what to do in particular dilemmas, because they argue that virtue ethics fails to come up with any rules for conduct. Hursthouse (1999) believes that this is wrong. In her view, people have access to a whole range of virtues and vices and, within the structure of these virtues and vices, there is considerable moral guidance. For example, the virtues include compassion, honesty, and patience. The virtuous person would therefore characteristically be compassionate, true to her word, and patient in the circumstances. Virtuous persons would not be noncompassionate or cruel, lie or impatient. Hursthouse believes that despite one's own initial uncertainty, it is possible to have a very good idea of what the virtuous person would do. For example, Hursthouse asks,

Would she lie in her teeth to acquire an unmerited advantage? No for that would be both dishonest and unjust.... Might she keep a death-bed promise even though living people would benefit from its being broken? Yes, for she is true to her word. And so on. (Hursthouse, 1999, p. 36)

Virtue terms, such as 'kind', honest', and 'patient', and the opposite vice terms, 'unkind' (or 'cruel'), 'dishonest', and 'impatient', provide greater explanatory force compared with obligations and deontic (dutybased) terms (Hursthouse, 1999). Anscombe (1997) heavily influences Hursthouse's view, according to Anscombe, instead of using deontic terms,

It would be a great improvement if, instead of 'morally wrong' one always named a genus such as 'untruthful', 'unchaste', 'unjust' . . the answer would sometimes be clear at once'. (Anscombe, 1997, p. 43) 
Hursthouse believes that people can gain a lot of 'invaluable action guidance ... from avoiding courses of action that are irresponsible, feckless ... harsh ... feeble ... self-indulgent' (Hursthouse, 1999, p. 42). In other words, one can gain considerable insight into what to do by thinking hard about the virtue and vice terms and the sorts of deeds expected of someone who exercises these traits. Furthermore, Hursthouse believes that virtue ethics 'comes up with a large number of rules' (Hursthouse, 1999, p. 36). Virtue ethics clearly gives one prescriptions for action, e.g. 'do what is kind', 'do what is honest', and 'do what is patient'. But virtue ethics also tells one what not to do, e.g. 'each vice [is] a prohibition - do not do what is dishonest, uncharitable, mean' (Hursthouse, 1999, p. 36). Hursthouse (1999) calls these the v-rules and, in developing this thesis, she demonstrates that virtue ethics does present an account of right action that includes rules, so denying the common criticism that it fails to.

It can be seen that the language of the virtues and vices provides a richer degree of action guidance than the barren language of obligation-based ethics. As a child, one regularly hears virtue and vice terms from parents and other adults and as one develops through adulthood, words such as 'fair' and 'kind' are replaced with deontic language, especially the central concepts of 'right' and 'wrong' action. I agree with Benn (1998) that the use of virtue and vice terms can prove to be helpful in an attempt to gain action guidance. Virtue ethics aims to make moral goodness and badness prior to the traditional pivotal moral considerations of moral rightness and wrongness. In exercising the virtues, the moral agent needs to strike a balance between the excessive and deficient extremes of the trait of character, what Aristotle (1980) calls 'hitting the mean'. For example, in exercising the virtue of courage, the moral agent needs to refrain from being reckless (the excessive extreme) or cowardly (the deficient extreme). Hitting the mean essentially concerns the use of moral judgement and reason in exercising traits of character. This complex endeavour is different from the pivotal endeavour of obligationbased moral theories i.e. to determine the moral rightness or wrongness of an action/omission. Indeed, instead of such deontic considerations, strong ver- sions of virtue ethics focus upon the notions of moral goodness and badness (this is discussed further in Virtue ethics: tenets, types, merits, and problems section).

\section{Problems with the virtues: identifying the virtues}

Disagreement exists on which character traits are virtues. For example, one person compiling a list of virtues might believe that honesty, patience, and tolerance are virtues. Another person may disagree, instead favouring compassion and justice. However, I am sceptical that a person who advocates the virtuous approach would, on the one hand, defend honesty and, on the other hand, reject compassion. A virtue on my view is a character trait, habitually performed, which disposes one to act, think, and feel in morally excellent ways. Those who exercise the virtues deserve praise and admiration. The fact that there are so many plausible virtues is not sufficient reason to claim that these traits are not all virtues.

Instead of the above claim, perhaps a more powerful claim is that there are only several virtues. This view runs counter to the common view that numerous different virtues exist. For instance, the above claim is that only honesty, patience, and tolerance are virtues, therefore ruling out other candidates such as compassion and justice. I would reject this claim. It seems to me implausible to believe that the moral life can be exhausted by reference to three character traits. One who suggests that there are only three (or fewer) virtues needs to respond to several questions, e.g. how can humans live morally good lives without being just? In other words, without the virtue of justice, is it possible to be morally good and if so, how? If the response to this question is affirmative, then one must be committed to a view of moral goodness that excludes the common idea that moral goodness involves being a just and fair person.

\section{Obligation-based moral theories in general and nursing ethics}

Obligation-based moral theories are popular in both contemporary general and nursing ethics. The concept of 'obligation' runs deep in contemporary west- 
ern society. Moral obligations, principles and rules and the nature and consequences of actions are morally important features. However, obligations are socially constructed and imposed upon one by a range of authorities such as law, ethicists, and the NMC (2004). But, an obligation does not exist nor does it do anything in isolation, a person needs to conceive, interpret, and apply the obligation to others in morally complex situations.

Obligation-based moral theories have several well-established flaws. Regarding consequentialism (e.g. Frey, 2000), these include the difficulty in predicting the actual consequences of actions and omissions and an extreme focus on the notion of 'right action' Hursthouse, 1999). Furthermore, act (e.g. Frey, 2000), rule (e.g. Lyons, 1965), and indirect forms of consequentialism (e.g. Hare, 1981) fail to take seriously several other morally important features. For instance, they: (1) fail to provide a rich account of moral character; (2) fail to provide a rigorous account of the distinctiveness of persons and the significance of relationships in human life (e.g. Scheffler, 1992); and (3) fail to acknowledge the important role played by emotions in the moral life of people. On the latter, Hursthouse (1999) argues that virtuous moral agents ought to feel 'moral remainder' both during and after their involvement in a range of moral dilemmas. The virtuous agent will feel emotions such as regret, anguish, guilt, hurt, loss, despair, and remorse. It is morally appropriate to feel these emotions because the virtuous agent is fully aware of the distressing nature of moral dilemmas, which are saturated with potentially damaging moral conflicts and uncertainties.

Some of the well-known flaws of deontology (e.g. Davis, 1990) are that (1) it does not provide adequate action-guidance until its second premise where it actually specifies what a correct moral obligation, principle or rule is; (2) it over-focuses on the notion of 'right action' rather than on the notion of moral goodness; (3) it fails to tell one how to settle conflicts between moral principles and obligations (Hursthouse, 1999); and (4) as with consequentialism, it also fails to account properly for the significance of relationships in human life (e.g. Williams, 1981). Because of these (and other) flaws and omissions, obligation- based moral theories in general ethics are incomplete and inadequate.

This critical evaluation of obligation-based moral theories fares little better in nursing ethics. Despite the recognition that nurses should display the moral virtues, these moral theories, particularly the 'four principles' approach (Gillon, 1986; Edwards, 1996; Beauchamp \& Childress, 2001), remain extremely popular and widespread in the nursing ethics literature (e.g. Armstrong et al., 2000) and nurse education (e.g. Parsons et al., 2001). Their popularity continues despite sustained critiques (e.g. Clouser \& Gert, 1990; Clouser \& Gert, 1994).

Why are obligation-based moral theories so popular despite their flaws? At least three reasons spring to mind. First, obligation-based moral theories are popular in general ethics; it makes sense to suppose that popular theories in general ethics will then be utilized in professional ethics. Second, despite the widespread view that patient-centred and holistic nursing care ought to be key objectives of contemporary nursing practice, a biomedical focus on practice remains predominant (Llamas et al., 2001). The epistemological paradigm that grounds the biomedical model and medical practice is empiricism, with a firm focus on, for example, the disease process, making diagnoses, identifying clinical needs and planning and delivering effective treatments. Consequentialism focuses upon the outcomes of actions, while one of the main foci in healthcare practice is on clinical outcomes. Therefore, it makes sense that doctors and nurses have adopted a consequentialist approach to moral reasoning that is very much in keeping with empiricism. Third, hospitals are large, complex institutions, which operate efficiently in part because of a system of rules, regulations, and policies. Such rules are generally utilitarian or at least consequentialist in content and scope. Rules aim to maximize the effectiveness of the institution. Such familiarity of and reliance upon rules helps to explain why medics and nurses favour rule-based deontological ethics over other alternative moral theories.

Obligation-based moral theories, e.g. the 'four principles' approach (Beauchamp \& Childress, 2001), can provide nurses, in particular novices, with a structured framework that can assist the identification of ethical 
issues and promote the resolution of complex moral dilemmas. However, there are several disadvantages of utilizing traditional accounts of obligation-based moral theories in nursing practice. I shall highlight just three. First, obligation-based moral theories place a firm emphasis on resolving moral dilemmas. There is a danger that an assumption is made that all moral dilemmas can be 'satisfactorily' resolved. However, such a simplistic view is problematic. Hursthouse (1999) distinguishes between resolvable, irresolvable, and tragic dilemmas. This distinction is ignored in much of the obligation-based nursing ethics literature with the result that the important issue of how a nurse and patient might feel during and after these sorts of moral dilemmas is overlooked. This criticism is, however, addressed by several care-orientated theorists in nursing ethics who appreciate the distinction between moral dilemmas and the important role played by emotion in the moral lives of nurses and patients (e.g. Nortvedt, 1998; Johnstone \& Fry, 2002). Second, act-utilitarianism and some traditional accounts of deontology neglect the role of moral wisdom and judgement in the moral life of nurses. This is in sharp contrast to the reality of contemporary nursing practice (e.g. Armstrong et al., 1999; Walker et al.,2000). It seems that the reality of clinical nursing is not acknowledged by obligation-based moral theories. Third, obligation-based theories, especially deontology, fail to provide sufficient action-guidance and direction to resolve the myriad of conflicts between duties that arise in nursing practice. Attempts at lexical ordering (Hare, 1981) and specifying moral principles (Beauchamp \& Childress, 2001) do not go far enough. Nurses are left without the necessary conceptual tools with which to clarify and resolve the numerous complex, multidimensional moral conflicts.

\section{Virtue ethics: tenets, types, merits, and problems}

Having articulated several important flaws central to obligation-based moral theories, a sensible question is 'where should one turn to discover a more complete account of the moral life?' My response is to nominate virtue ethics, the moral theory that has the virtues at its core.
Critics allege that there is no such thing as a theory of virtue; for example, Rachels states that there is 'no settled body of doctrine on which all these writers [virtue ethicists] agree' (Rachels, 1999, p. 177). Of course, this criticism can also be levelled at the many distinct versions of obligation-based moral theories. What is not in doubt, however, is that versions of virtue ethics share a set of concerns, which are largely ignored in obligation-based ethics. I shall use the term 'tenet', because these concerns mark out virtue ethics as a distinct moral theory and a credible alternative to consequentialism and deontology. I shall list four central tenets of virtue ethics:

1 It provides a detailed account of moral character; 2 It provides a rich account of moral goodness;

3 It provides a plausible account of moral education; 4 It provides a natural and convincing account of moral motivation.

\section{Supplementary and strong versions of virtue ethics}

Versions of virtue ethics can be divided into supplementary and strong theories. Supplementary theories hold that the virtues and a corresponding virtue ethics require assistance from a version of obligation-based moral theories. This 'essentialist' (Pence, 1991) approach combines an account of right action provided by consequentialism or deontology with an emphasis on moral character provided by the virtues and virtue ethics. The account of the virtues is offered as a supplement to an obligation-based theory of right action.

\section{Supplementary virtue ethics: weak and moderate versions}

Supplementary versions of virtue ethics can be further subdivided into those that hold that (1) obligations and right action are more important than the virtues and moral character in morality and those that hold that (2) the virtues and moral character are more important in morality than obligations and right action. The former can be called 'weak' and the latter 'moderate' versions of virtue ethics.

Examples of supplementary virtue ethics in medicine include Pellegrino \& Thomasma (1993). These 
ethicists believe that moral principles possess greater moral force than the virtues. Without moral principles, virtue ethics is left unable to adequately prescribe action-guidance for doctors. Pellegrino and Thomasma see a strong link between moral principles and corresponding virtues, each supplementing and informing the other.

Examples of supplementary virtue ethics in nursing include Brody (1988), Lutzen \& Barbosa da Silva (1996) and McKie \& Swinton (2000). Brody (1988) published an influential paper in which she examined the supplementary role of the virtues and caring in adult nursing. I believe this is a moderate version of a tentative, underdeveloped account of the virtues. Lutzen \& Barbosa da Silva (1996) discuss the concept of virtue and the role of virtue ethics, as a necessary but insufficient complement to rule-based ethics in psychiatric nursing. The authors argue that the virtues enable a nurse to evaluate an ethical dilemma, identify all the morally relevant features, and then apply the appropriate ethical rules and principles to the dilemma. The authors claim that virtues help to provide the right motivation for the nurse in order to decide which moral rule to obey and follow. This supplementary approach has its merits; for example, at least the authors recognize the importance of the virtues in moral decision making in nursing. It is, however, unclear whether the authors would argue for a weak or moderate position. My view is that this version represents a weak version of virtue ethics because virtue is held to be necessary and less pivotal to morality in nursing than the role of moral obligations, principles or rules. Finally McKie \& Swinton's (2000) account is steeped in Aristotle (1980) and pays homage to MacIntyre (1985), both of whom advocate a strong virtue ethics; however, despite this, McKie and Swinton argue for a moderate, supplementary account.

\section{Strong virtue ethics}

Strong versions of virtue ethics (e.g. Aristotle, 1980; MacIntyre, 1985; Slote, 1992; Hursthouse, 1999; Slote, 2001; Swanton, 2003) argue that virtue ethics and the virtues are capable of doing all the work of ethics.
Rachels calls this, 'an independent theory of ethics that is complete in itself' (Rachels, 1999, p. 189). According to strong virtue ethics, one's moral character, moral motivations, and the justification of acts are couched solely in the virtues. Strong virtue ethicists reject the use of deontic language such as 'right' and 'wrong'. They follow Anscombe (1997) in wanting to jettison all deontic notions from ethics. Strong virtue ethicists would justify for instance, not lying to someone, not because it is 'wrong', 'unethical' or 'it breaks the moral rule "do not lie to others" but because 'it is dishonest'. Instead of deontic terms, the language of the virtues and vices is employed.

The two central questions in normative ethics what should I do? and how should I be? - are not necessarily incompatible, despite the objection from obligation-based ethicists that action guidance is ignored in virtue ethics. One could generalize and claim that obligation-based moral theories are actcentred and virtue ethics is agent-centred, because the latter makes moral character/goodness so important. But it would be unfair to claim that virtue ethics is agent-centred rather than act-centred (Hursthouse, 1999). Some obligation-based ethicists do interpret virtue ethics in this simplistic way. Perhaps they misconceive virtue ethics because its revival only began in 1958 (Anscombe, 1997) and as such, it is an immature moral theory and one that is poorly understood compared with the traditional and well-known obligation-based moral theories.

Supplementary versions of virtue ethics are hybrids and as such are potentially theoretically incompatible accounts. A strong version of virtue ethics is a plausible option because it is a coherent single theory. Strong versions of virtue ethics provide adequate action guidance because they encourage agents to think hard about the nature and content of the virtues and vices and encourage agents to act according to the v-rules. Because of these reasons, I favour a strong version of virtue ethics.

\section{Objections to virtue ethics}

However, there are several common objections to virtue ethics (e.g. Pence, 1991; Louden, 1997; Pettit, 
1997; Benn, 1998; Rachels, 1999). I shall focus on only one objection, namely, the conflicts of virtues problem.

Several ethicists including Benn (1998) and Rachels (1999) identify conflicts between the virtues as a serious problem for virtue ethics. How is one meant to resolve situations where two or more virtues have been identified as important? For instance, is honesty, in a given situation, more important than justice?

I shall respond by making three points, although several other responses are open to the virtue ethicist (e.g. Armstrong, 2004). First, it is not true to say that a person will have no idea what to do simply because both honesty and kindness are virtues. One needs to think hard about what honest and kind persons are like; for example, what characteristically would honest and kind persons do? What behaviours does one expect from honest and kind persons? What acts would honest and kind persons carry out? One should take into account particular circumstances and contexts; these details will help to shed some light on which virtue is thought more important in a given situation. My second point is that both kindness and honesty are moral virtues, examples of moral excellences that should be praised and admired. Acting from the virtue of kindness and acting from the virtue of honesty are both examples of acting well. Acting cruelly and dishonestly are vices, examples of acting badly. Thus, the conflict is between two moral excellences, which in different ways will help their possessor and benefactor(s) to flourish. Third, actconsequentialists hold that applying the single rule of their theory will reveal the morally right course of action. This reading of act-consequentialism means that no room is given to utilizing judgement in moral decision making. While it is true to say that several contemporary deontologists recognize the importance of versatility, flexibility, judgement, and moral perception in moral decision making (e.g. Herman, 1993; Baron, 1995), it remains the case that several traditional accounts of obligation-based moral theories, some of which are taught to nurses (Parsons et al., 2001), condemn the use of judgement to resolve conflicts between moral obligations and principles. However, virtue ethics acknowledges that conflicts between virtues will arise and it holds that exercising judgement is fundamentally important to morality and to human flourishing.

\section{The virtue-based approach to moral decision making in nursing practice}

In this section, I shall first provide a brief overview of the virtue-based approach to moral decision making in nursing practice. I shall then describe moral wisdom in more detail. Next, I shall briefly describe the virtue-based helping relationship and I conclude this section by mentioning some merits and criticisms of the virtue-based approach.

Three features characterize the virtue-based approach to moral decision making: (1) exercising the moral virtues, e.g. compassion (e.g. Blum, 1980; Pellegrino \& Thomasma, 1993; Lutzen \& Barbosa da Silva, 1996; von Dietze \& Orb, 2000); (2) utilizing moral judgement; and (3) utilizing moral wisdom (e.g. Murdoch, 1970; Hursthouse, 1999). I shall now examine moral wisdom in more detail.

\section{Moral wisdom}

Moral wisdom is a complex phenomenon that includes (at least) three components: moral perception, moral sensitivity, and moral imagination. I believe that each component is equally important to the major aim of moral wisdom, i.e. to help a nurse to think of and deliver a diverse range of morally good practices, interventions, and activities. Much has been written about the three components that make up moral wisdom. I shall not develop this debate further; instead, I shall merely present a brief overview of each component.

Moral perception (e.g. Blum, 1980; Lutzen \& Nordin, 1993; Nortvedt, 1998) refers to one's capacity to see, and provide meaning in, the 'morally relevant features' of observations, situations, interactions, and experiences. I believe that these morally relevant features include: moral virtues, the outcomes of actions, intuitions, moral rights, motives, religious beliefs, experiences, and clinical information (e.g. Armstrong et al., 2000). Morally perceptive nurses are able to see a wide range of morally relevant features and discern meaning in them. Regarding moral sensitivity (e.g. Nortvedt, 1998; Jaeger, 2001), to be sensitive to a 
person's needs suggests that one is able to identify one's needs, perhaps more easily than another person is able to. The phrase 'morally sensitive' connotes a positive and admirable quality. In contrast, if I am insensitive to a patient's feelings, then I might fail to perceive her feelings and, as a result, I might act as though her feelings do not matter to me. To be a morally sensitive nurse, it is insufficient to merely perceive patients' needs. One's perceptions ought to produce a morally appropriate response; perceptions also help to form one's moral motives. Morally sensitive nurses assimilate a wide range of information, act upon it, and respond to patients' needs and interests in morally good ways. Regarding moral imagination, empathy and moral imagination (e.g. Baillie, 1996; Yegdich, 1999) are closely linked. Or at least the former involves the latter. Perhaps empathy is a necessary, but not sufficient component of imagination. It seems to me that the activity of imagination requires one to put oneself in another person's position (e.g. Scott, 2000). Important questions include 'how would I feel if the nurse lied to me?' and 'how would I feel if the nurse spoke to me in such a callous way?' Moral imagination can be utilized by nurses to reflect on what it might be like to be a patient in a specific set of circumstances.

\section{The virtue-based helping relationship}

I view the helping relationship between a nurse and a patient as one grounded in moral virtues; I refer to this as a virtue-based helping relationship. Depending upon the morally relevant features, nurses will need to exercise a wide range of moral virtues if they wish to respond to patients in morally good ways. I shall not attempt to present a long list of 'essential' virtues because this list would be extremely long and subjective and, as a result, I am not sure that it would be a valuable endeavour. However, for illustrative purposes, some examples of moral virtues that are important for the development and sustenance of morally good helping relationships are compassion (including benevolence or kindness), courage, respectfulness, patience, tolerance, justice, trustworthiness, and honesty. I will not examine these virtues in detail, although I aim to do so in a subsequent paper.
Instead, I will sketch the relevance of three virtues to nursing practice. First, I suggest that the virtue of compassion is the moral foundation of the helping relationship between nurse and patient. Second, I suggest that courage is a moral virtue needed by a nurse if she wishes to be an advocate for a patient (e.g. Breen, 1992; Hewitt, 2002) and third, I suggest that the virtue of respectfulness is one of the virtues necessary to empower patients. I realize that to develop a more rigorous account of the virtue-based approach, further investigation, both philosophical and empirical, is required on the nature of the moral virtues and their place within nursing practice.

\section{Merits of the virtue-based approach in nursing practice}

There are several important merits of the virtue-based approach (Armstrong, 2004). I shall mention just four. First, this approach accurately reflects the language of the virtues and vices, e.g. 'fair', 'well', and 'care' that nurses use on a daily basis (Armstrong et al., 2000). Second, this approach places a firm emphasis upon the crucial role played by emotion including moral remainder (Hursthouse, 1999) in the moral lives of patients and nurses. Third, this approach makes pivotal the importance of using judgement and moral wisdom to enable nurses to make morally good choices and decisions with patients in different circumstances. Fourth, this approach places a firm emphasis upon moral education, e.g. the importance of morally (and clinically) good role models (e.g. Lutzen \& Barbosa da Silva, 1996; Parsons et al., 2001). While obligation-based moral theories focus primarily on the notions of moral rightness and wrongness, the virtue-based approach focuses upon moral goodness and badness. And, unlike some traditional accounts of obligation-based moral theories, which can fairly be described as rigid and inflexible, the virtue-based approach can be described as contextdependent, relational, and particularist.

\section{Criticisms of the virtue-based approach in nursing practice}

Of course, like all moral theories, the virtue-based approach can also be criticized. I have already dis- 
cussed the conflicts of virtues problem and the criticism that this approach makes assumptions about the nature of virtues and goodness (Armstrong, 2004). I shall briefly mention two further problems. First, because of the ambiguity and disagreement in identifying the virtues, this approach is guilty of moral relativism (e.g. Benn, 1998; Rachels, 1999). Second, this approach is alleged to be unable to account for persons who exercise excessive virtue; for example, a nurse who is completely honest with patients in all contexts (I aim to discuss this major concern in a subsequent paper).

\section{Maclntyre's account of the virtues and the virtue-based approach in nursing practice}

While the philosophical foundation for the virtuebased approach is adequate, the work of MacIntyre (e.g. MacIntyre, 1985) provides a more secure, deeper foundation. MacIntyre's account of the virtues as set forth in After Virtue (MacIntyre, 1985) is interpreted in the form of three theses: (1) the role and importance of a narrative conception of the self in morality; (2) the meaning and nature of practices, goods, and the virtues; and (3) the role and importance of a tradition of enquiry in morality.

MacIntyre's account of the virtues (e.g. Horton \& Mendus, 1994) is context-dependant, relational, and particularist. Although MacIntyre fails to discuss medicine or nursing as a practice, his account of the virtues is highly suitable for the virtue-based approach to moral decision making in nursing practice. For example, I suggest that his account recognizes the importance of allowing patients to tell their narratives, it acknowledges the importance of interpersonal responses and it acknowledges that questions about personal identify are fundamentally important for nurses, e.g. 'who am I?', 'what kind of nurse am I?', and 'how ought I to relate to this patient and my colleagues?'

I conceive nursing as a purposive practice (Miller, 1994). Nursing is a complex and coherent form of socially established human activity that aims at providing social goods and demonstrating human excellences. While it is difficult to articulate the internal goods of nursing (e.g. Sellman, 2000), it is plausible to suggest that these relate to nurses feeling certain positive emotions, which they feel when they are helping patients (e.g. Moir \& Abraham, 1996). I suggest that the development and sustenance of a virtue-based helping relationship, the exercise of moral wisdom and feeling valued by patients and relatives are examples of the internal goods of contemporary nursing practice.

Nurses ought to examine the nature of specific virtues and examine the specific needs of patients in their particular clinical environment. To counter the charge of moral relativism, self-reflection and reflection on the role of a nurse and the ends of nursing will help to shed some light on which traits of character are virtues. I suggest that nurses who exercise the virtues will help to sustain the practice of nursing and prevent the marginalization of the virtues.

Regarding the MacIntyrian idea of a tradition of enquiry, each individual nurse is part of a history. Each person is a bearer of a tradition of enquiry, an intellectual set of ideas - an argument - that situates the practice of nursing. The history of nursing as a profession, the history of nurse education, and the histories of each person entering the nursing profession all operate within a tradition of enquiry. Traditions are dynamic; they change to meet the needs of generations. The virtue-based approach is an example of a tradition of moral enquiry, while the biomedical model is a tradition of empirical or scientific enquiry.

\section{Conclusions}

In this paper, I have argued for a strong - actionguiding - version of virtue ethics for nursing practice. I am aware that the virtue-based approach has several problems that need to be addressed. Future research - both empirical and philosophical - is needed to further investigate several issues espoused in this paper. For example, more insight is required on the role and value of specific virtues in different nursing environments, on the nature and resolution of conflicts between virtues, and more information could be gathered from patients on whether they perceive virtuous nursing care (e.g. Beech \& Norman, 1995; Arm- 
strong et al., 2000). Moreover, more work is needed to understand the nature of making moral judgements, the role of moral wisdom in moral decision making, whether students of nursing can learn to be virtuous (e.g. Lutzen \& Barbosa da Silva, 1996), and how the virtue-based approach can be taught more widely in both pre- and post-registration nurse education (e.g. Parsons et al., 2001).

Despite these concerns, a strong version of virtue ethics and the virtue-based approach to moral decision making in nursing practice have many significant merits. These merits help to distinguish this approach as a plausible alternative to the traditional obligationbased moral theories that have long dominated nursing ethics. As noted in Illness, emotions, and the nursing-patient relationship section, there is a major emphasis in contemporary nursing on patient-centred, collaborative, and 'high'-quality care. It seems to me that 'high'-quality care and virtuous care are synonymous. Because of these (and other) reasons, virtue ethics and the virtue-based approach to moral decision making in nursing practice ought now to be acknowledged, taken more seriously, and investigated further.

\section{Acknowledgement}

I would like to thank an anonymous reviewer for several helpful and insightful critical comments, which have greatly improved the paper.

\section{References}

Altschul A. (1972) Patient-Nurse Interaction. Churchill Livingstone, Edinburgh.

Anscombe G.E.M. (1997) Modern moral philosophy. In: Virtue Ethics (eds R. Crisp \& M. Slote), pp. 26-44. Oxford University Press, Oxford.

Aristotle (1980) The Nicomachean Ethics (tr. D. Ross, rev. J.L. Ackrill \& J.O. Urmson). Oxford University Press, Oxford.

Armstrong A.E. (2004) Towards a strong practice-based virtue ethics for nursing practice. Unpublished $\mathrm{PhD}$ Thesis, University of Newcastle upon Tyne.

Armstrong A.E., Parsons S. \& Barker P.J. (1999) The moral reasoning of mental health nurses. Unpublished research findings, University of Newcastle upon Tyne.

Armstrong A.E., Parsons S. \& Barker P.J. (2000) An inquiry into moral virtues, especially compassion, in psychiatric nursing: findings from a Delphi study. Journal of Psychiatric and Mental Health Nursing, 7, 297-306.

Baillie L. (1996) A phenomenological study of the nature of empathy. Journal of Advanced Nursing, 24, 1300-1308

Baron M. (1995) Kantian Ethics almost without Apology. Cornell University Press, Ithaca, New York.

Beauchamp T.L. \& Childress J.F. (2001) Principles of Biomedical Ethics, 5th edn. Oxford University Press, New York.

Beech P. \& Norman I.J. (1995) Patient's perceptions of the quality of psychiatric nursing care: findings from a smallscale descriptive study. Journal of Clinical Nursing, 4, 117-123.

Benn P. (1998) Ethics. UCL Press Ltd., London.

Blum L. (1980) Friendship, Altruism and Morality. Routledge \& Kegan Paul, London.

Breen H. (1992) The psychiatric nurse - patient advocate? Canadian Journal of Psychiatric Nursing, 31, 9-11.

Brody J.K. (1988) Virtue ethics, caring, and nursing. Scholarly Inquiry for Nursing Practice, 2, 87-96.

Bulow P.H. (2003) In dialogue with time: identity and illness in narratives about chronic fatique. Narrative Inquiry, 13, $71-77$.

Clouser K.D. \& Gert B. (1990) A critique of principlism. Journal of Medicine and Philosophy, 15, 219-236.

Clouser K.D. \& Gert B. (1994) Morality vs. principlism. In: Principles of Health Care Ethics (ed. R. Gillon), pp. 251266. John Wiley \& Sons, Chichester.

Clouston T. (2003) Narrative method: talk, listening and representation. British Journal of Occupational Therapy, 66, 136-142.

Crowley B.J., Hayslip B. \& JrHobdy J. (2003) Psychological hardiness and adjustment to life events in adulthood. Journal of Adult Development, 10, 237-248.

Davis N.A. (1990) Contemporary deontology. In: A Companion to Ethics (ed. P. Singer), pp. 205-218. Blackwell Publishers, Oxford.

von Dietze E. \& Orb A. (2000) Compassionate care: a moral dimension of nursing. Nursing Inquiry, 7, 166-174.

Edwards S.D. (1996) Nursing Ethics - A Principle-Based Approach. Macmillan, Basingstoke.

Frey R.G. (2000) Act-utilitarianism. In: Ethical Theory (ed. H. LaFollette), pp. 165-182. Blackwell Publishers, Oxford.

Gillon R. (1986) Philosophical Medical Ethics. John Wiley \& Sons, Chichester.

Hare R.M. (1981) Moral Thinking. Oxford University Press, Oxford.

Herman B. (1993) The Practice of Moral Judgment. Harvard University Press, Cambridge, MA.

Hewitt J. (2002) A critical review of the arguments debating the role of the nurse advocate. Journal of Advanced Nursing, 37, 439-445. 
Hirschfeld M. (2003) Homecare versus institutionalizm: family caregiving and senile brain disease. International Journal of Nursing Studies, 40, 463-469.

Horton J. \& Mendus S. (1994) Alasdair MacIntyre: after virtue and after. In: After Macintyre - Critical Perspectives on the Work of Alasdair Macintyre (eds J. Horton \& S. Mendus), pp. 1-15. Polity Press, Cambridge.

Hurst K. \& Howard D. (1988) Measure for measure. Nursing Times, 84, 30-32.

Hursthouse R. (1999) On Virtue Ethics. Oxford University Press, Oxford.

Irwin T. (1999) Greek Ethics. Oxford University Press, Oxford.

Jaeger S.Z. (2001) Teaching health care ethics: the importance of moral sensitivity for moral reasoning. Nursing Philosophy, 2, 131-143.

Johnstone M.J. \& Fry S.T. (2002) Ethics in Nursing Practice: A Guide to Ethical Decision-Making. Blackwells, Oxford.

Llamas K.J., Pickhauer A.M., Pillar N. \& B. (2001) Mainstreaming palliative care for cancer patients in the acute hospital setting. Palliative Medicine, 15, 207-212.

Louden R.B. (1997) On some vices of virtue ethics. In: Virtue Ethics (eds R. Crisp \& M. Slote), pp. 201-216. Oxford University Press, Oxford.

Lutzen K. \& Barbosa da Silva A. (1996) The role of virtue ethics in psychiatric nursing. Nursing Ethics, $\mathbf{3}$, 202-211.

Lutzen K. \& Nordin C. (1993) Structuring moral meaning in psychiatric nursing. Scandinavian Journal of Caring Sciences, 7, 175-180.

Lyons D. (1965) Forms and Limits of Utilitarianism. Clarendon Press, Oxford.

Martin T. (1992) Psychiatric nurses' use of working time. Nursing Standard, 6, 34-36.

MacIntyre A. (1985) After Virtue - A Study in Moral Theory, 2nd edn. Duckworth, London.

McKie A. \& Swinton J. (2000) Community, culture and character: the place of the virtues in psychiatric nursing practice. Journal of Psychiatric and Mental Health Nursing, 7, $35-42$.

Miller A. (1985) Nurse-patient dependency: is it iatrogenic? Journal of Advanced Nursing, 9, 479-486.

Miller D. (1994) Virtues, practices and justice. In: After Macintyre (eds J. Horton \& S. Mendus), pp. 245-264. Polity Press, Cambridge.

Moir J. \& Abraham C. (1996) Why I want to be a psychiatric nurse: constructing an identity through contrasts with general nursing. Journal of Advanced Nursing, 23, 295298.

Monaghan A. (1995) Communication. In: Potter and Perry's Foundations in Nursing Theory and Practice (ed. H.B.M. Heath), pp. 275-297. Mosby, London.

Murdoch I. (1970) Sovereignty of Good. Routledge \& Kegan Paul, London.
Narayanasamy A. (2004) Spiritual coping mechanisms in chronic illness: a qualitative study. Journal of Clinical Nursing, 13, 116-117.

Norman A.J. (1980) Rights and Risks. Centre for Policy and Ageing, London.

Nortvedt P. (1998) Sensitive judgment: an inquiry into the foundations of nursing ethics. Nursing Ethics, 5, 385-392.

NMC (2004) The NMC Code of Professional Conduct: Standards for Conduct, Performance and Ethics. Nursing and Midwifery Council, London.

Oakley J. \& Cocking D. (2001) Virtue Ethics and Professional Roles. Cambridge University Press, Cambridge.

Parsons S., Barker P.J. \& Armstrong A.E. (2001) The teaching of health care ethics to students of nursing in the UK: a pilot study. Nursing Ethics, 8, 45-56.

Pellegrino E. \& Thomasma D.C. (1993) The Virtues in Medical Practice. Oxford University Press, New York.

Pence G. (1991) Virtue theory. In: A Companion to Ethics (ed. P. Singer), pp. 249-259. Blackwells, Oxford.

Pettit P. (1997) The consequentialist perspective. In: Three Methods of Ethics (co-authors M. Baron, P. Petit \& M. Slote), pp. 92-174. Blackwells, Oxford.

Pincoffs E. (1986) Quandaries and Virtues: Against Reductivism in Ethics. University of Kansa Press, Lawrence.

Rachels J. (1999) The Elements of Moral Philosophy, 3rd edn. McGraw-Hill, New York.

Sanson-Fisher R., Poole A. \& Thompson V. (1979) Behaviour patterns within a general hospital psychiatric unit: an observational study. Behaviour Research and Therapy, 17, 317-332.

Scheffler S. (1992) Human Morality, .Oxford University Press, New York.

Scott P.A. (2000) Emotion, moral perception and nursing practice. Nursing Philosophy, 1, 123-133.

Sellman D. (2000) Alasdair MacIntyre and the professional practice of nursing. Nursing Philosophy, 1, 26-33.

Skidmore D. (1992) Communication. In: A Textbook of Psychiatric and Mental Health Nursing (eds J.I. Brooking, S.A.H. Ritter \& B.L. Thomas), pp. 249-259. Churchill Livingstone, Edinburgh.

Slote M. (1992) From Morality to Virtue. Oxford University Press, New York.

Slote M. (2001) Morals with Motives. Oxford University Press, New York.

Speedy S. (1999) The therapeutic alliance. In: Advanced Practice in Mental Health Nursing (eds M. Clinton \& S. Nelson), pp. 59-76. Blackwell Science, Oxford.

Swanton C. (2003) Virtue Exhics: A Pluralistic View. Clarendon Press, Oxford.

Walker L., Barker P.J. \& Pearson P. (2000) The required role of the psychiatric-mental health nurse in primary health care: an augmented Delphi study. Nursing Inquiry, 7, 91102. 
Whittington D. \& McLaughlin C. (2000) Finding time for patients: an exploration of nurses' time allocation in an acute psychiatric setting. Journal of Psychiatric and Mental Health Nursing, 7, 259-268.

Williams B. (1981) Moral Luck. Cambridge University Press, Cambridge.

Wright H. (1993) The therapeutic relationship. In: Mental Health Nursing (eds H. Wright \& M. Giddey), pp. 3-9. Chapman \& Hall, London.
Yegdich T. (1999) On the phenomenology of empathy in nursing: empathy or sympathy? Journal of Advanced Nursing, 30, 83-93.

Zakrzewski R.F. \& Hector M.A. (2004) The lived experiences of alcohol addiction: men of Alcoholics Anonymous. Issues in Mental Health Nursing, 25, $61-77$. 